$\cdots \quad 1 N-34$

NASA Technical Memorandum 106427

AIAA-93-1966

198131

$\| p$

\title{
Pressurization and Expulsion of a Flightweight Liquid Hydrogen Tank
}

N.T. Van Dresar and R.J. Stochl

Lewis Research Center

Cleveland, Ohio

(NASA-TM-106427) PRESSURIZATION

N94-20177

AND EXPULSION OF A FLIGHTWEIGHT

LIQUID HYDROGEN TANK (NASA) $11 \mathrm{p}$

Unclas

G3/34 0198131

Prepared for the

29th Joint Propulsion Conference and Exhibit

cosponsored by the AIAA, SAE, ASME, and ASEE

Monterey, California, June 28-30, 1993 
$\therefore-1, \cdots+1$

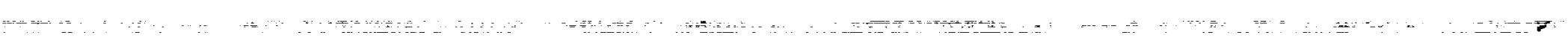

-

$=$ 


\title{
PRESSURIZATION AND EXPULSION OF A FLIGHTWEIGHT LIQUID HYDROGEN TANK
}

\author{
N. T. Van Dresar* \\ and \\ R. J. Stochl \\ National Aeronautics and Space Administration \\ Lewis Research Center \\ Cleveland, Ohio 44135
}

\begin{abstract}
Experimental results are presented for pressurization and expulsion of a flightweight $4.89 \mathrm{~m}^{3}$ liquid hydrogen storage tank under normal gravity conditions. Pressurization and expulsion times were parametrically varied to study the effects of longer transfer times expected in future space flight applications. It was found that the increase in pressurant consumption with increased operational time is significant at shorter pressurization or expulsion durations and diminishes as the duration lengthens. Gas-to-wall heat transfer in the ullage was the dominant mode of energy exchange, with more than 50 percent of the pressurant energy being lost to tank wall heating in expulsions and the long duration pressurizations. Advanced data analysis will require a multidimensional approach combined with improved measurement capabilities of liquid-vapor interfacial transport phenomena.
\end{abstract}

\section{Nomenclature}

$\begin{aligned} A & \text { area } \\ C & \text { specific heat } \\ E & \text { total energy } \\ h & \text { specific enthalpy } \\ M & \text { total mass } \\ m & \text { mass } \\ \dot{m} & \text { flowrate, mass transfer rate } \\ P & \text { pressure } \\ Q & \text { total heat leak } \\ \dot{q} & \text { heat flux } \\ R & \text { gas constant for hydrogen } \\ T & \text { temperature } \\ \bar{T} & \text { average temperature } \\ t & \text { time } \\ U & \text { total internal energy } \\ u & \text { specific internal energy } \\ V & \text { volume } \\ x & \text { mass fraction } \\ Z & \text { compressibility factor } \\ \rho & \text { density }\end{aligned}$

\footnotetext{
*member, AIAA
}

Copyright $O 1993$ by the American Institute of Aeronantics and Astronauties, Inc. No copyright is asserted in the United States under Title 17, U.S. Code. The government has a royalty-free license to exercise all rights under the copyright claimed herein for Governmental purposes. All other rights are regerved by the copyright owner. subscripts

$\begin{aligned} e & \text { interfacial transport (+ for evaporation) } \\ i & \text { summation index } \\ \text { id } & \text { ideal } \\ \text { im } & \text { initial mass in vapor region } \\ \text { in } & \text { entering tank } \\ n h & \text { normal-hydrogen } \\ \ell & \text { liquid } \\ o & \text { outflow } \\ p & \text { pressurant } \\ p h & \text { parahydrogen } \\ v & \text { vapor } \\ w & \text { wall } \\ 1 & \text { start } \\ 2 & \text { end }\end{aligned}$

\section{Introduction}

Future NASA missions will involve pressurization and expulsion of cryogenic tankage on-orbit or in other low-gravity environments. Understanding of low-gravity effects such as the undetermined liquid-vapor phase distribution and its impact on tank pressurization and expulsion will require space experimentation and vastly improved computational modeling capabilities of low gravity fluid dynamics and interfacial heat/mass transport. A related issue pertaining to cryogen transfer operations is the influence of longer duration pressurization and expulsion processes due to various operational constraints involved with low-gravity cryogenic fluid management. Longer operational times are expected due to requirements imposed by unvented transfer processes and liquid acquisition devices. Reference 1 provides a summary of pressurization technology and low-gravity issues.

This paper partially addresses the issue of longer pressurization and expulsion times by examining the effects occurring in the normal gravity environment. Experiments were conducted in a flightweight liquid hydrogen $\left(\mathrm{LH}_{2}\right)$ tank representative of future spacecraft tankage. This tank had a low mass-to-volume ratio and high performance multilayer thermal insulation. Pressurization tests from atmospheric pressure to 205 or 275 
$\mathbf{k P a}$ were performed at nominal fill levels of $\mathbf{5 0}$ and 87 percent (by volume). Expulsion tests were performed from 87 to 5 percent fill at constant tank pressures of 205 and $275 \mathrm{kPa}$. The main objectives of the tests were to determine the influence of ramp and expulsion times on the required pressurant mass. Ramp times (times to pressurize the tank to the expulsion pressure) were parametrically varied from 0.23 to $8.2 \mathrm{~min}$; the range of expulsion time was from 12 to 33 min. Ambient temperature hydrogen gas was used as the pressurant.

Similar $\mathrm{LH}_{2}$ tests were conducted in thicker-walled spherical tanks more than two decades ago 2,3 . Results of these studies indicated that inlet gas temperature, tank pressure level and injector geometry had the greatest impact on pressurant requirements. Tank wall thickness $(0.41-0.89 \mathrm{~cm}$ compared to $0.21 \mathrm{~cm}$ for the present work) was reported to have a lesser influence. Ramp durations for the present work are up to 9 times those of the earlier work and expulsions are up to 75 percent longer. The present data is analyzed in a similar manner and compared to the earlier results ${ }^{2,3}$.

\section{Anparatus}

Tests were conducted in a vacuum chamber with a cryoshroud enclosing the $\mathrm{LH}_{2}$ test tank and a smaller companion tank (unused for these tests). The shroud was kept at ambient temperature $(295 \mathrm{~K})$ thus maintaining a constant heat flux to the test article. Vacuum chamber pressures were on the order of $10^{-4}$ to $10^{-3} \mathrm{~Pa}$. The $\mathrm{LH}_{2}$ test tank is constructed of chemical-milled 2219 aluminum and insulated with multi-layer insulation. It is approximately an ellipsoidal volume of revolution having a major-to-minor axis ratio of 1.2 , a major diameter of $2.2 \mathrm{~m}$, a volume of $4.89 \mathrm{~m}^{3}$, and an internal surface area of $14.0 \mathrm{~m}^{2}$. A $0.71 \mathrm{~m}$ diameter flange at the top provides access to the inside. The tank mass is $149 \mathrm{~kg}$. Most of the wall is $2.08 \mathrm{~mm}$ thick except for the thick bolted flange and lid at the top, thickened lands for support lugs, and a thickened equatorial region. The tank insulation system, size, and lightweight construction (except for the lid) are representative of the type of system that may be used in future space transfer vehicles.

Pressurant gas from outside high pressure storage bottles entered the tank through a conical diffuser at the top. The diffuser outlet was $15.2 \mathrm{~cm}$ in diameter and is about $12 \mathrm{~cm}$ below the tank lid. Two wire cloth screens were positioned within the diffuser for flow smoothing. A silicon diode transducer mounted inside the diffuser measured incoming gas temperature. Pressurant gas flow rate was measured at a sharp-edged orifice equipped with high and low range differential pressure transducers. Liquid outflow exited at the tank bottom and was measured by a venturi meter in the transfer line.

Tank pressure was measured by pressure transducers located in the vent line. Liquid level was measured by a capacitance probe. Fluid temperatures were measured in both the vertical and radial directions by an array of silicon diode transducers as shown in Fig. 1. Four radial temperature rakes were suspended from the main vertical rake as shown. Two interface rakes having sensors spaced at $0.64 \mathrm{~cm}$ intervals were employed to obtained detailed measurements near the liquid-vapor interface at the 50 and 87 percent fill locations. The external wall temperature distribution was measured by a number of wallmounted silicon diode transducers as indicated in Fig. 1. Open symbols in Fig. 1 denote failed sensors not used in the data analysis. Boil-off tests were not conducted during the current tests- on the basis of other test results using the same hardware, the average wall heat flux is estimated to be $2.3 \mathrm{~W} / \mathrm{m}^{2}$.

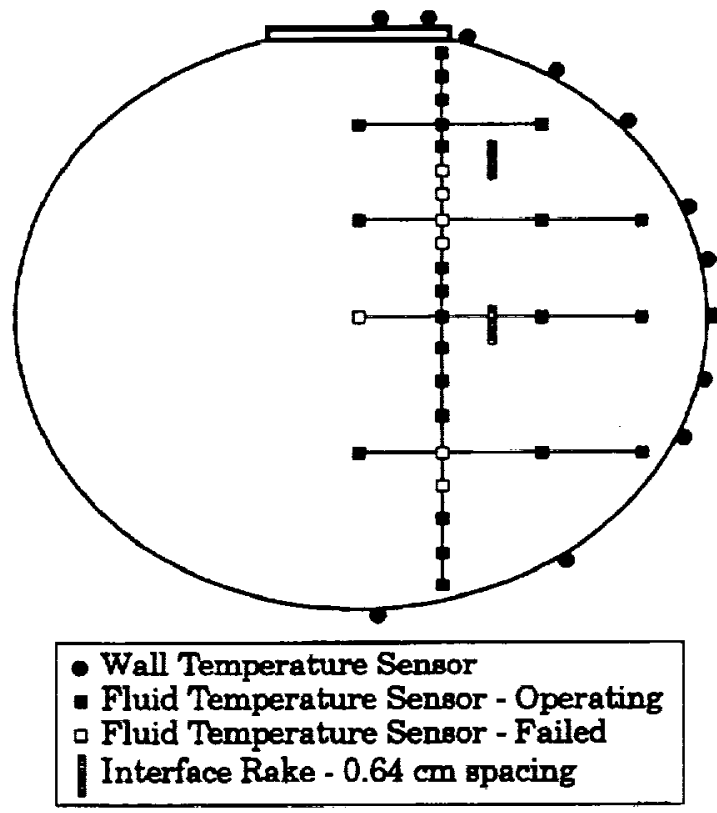

Figure 1 - Schematic of Test Tank Showing Temperature Sensor Locations.

\section{Test Procedures}

The tank was filled to the starting fill level while the tank pressure was kept above atmospheric pressure and then vented to atmosphere to induce bulk liquid boiling and isothermal liquid conditions. The tank remained vented for at least 15 min until saturated conditions at atmospheric pressure were established. A ramp test was 
initiated by closing the vent valve and opening the pressurant line valves. A preset pressure ramp rate was maintained by an automatic ramp generator connected to the flow control valve. Ramp tests were stopped when the final tank operating pressure was reached. For expulsions, control of the pressurant flow valve was switched to an automatic pressure controller which added pressurant to maintain constant tank pressure. Liquid outflow was regulated by remote operation of flow control valves in the outflow line. Expulsions were terminated when the liquid fill level dropped below 5 percent. Data was sampled and recorded at regular intervals by an automated data acquisition system. Ranges of ramp and expulsion times were determined by limitations of the maximum gas supply rate and the lower limit of flow rate measurement capabilities at the test facility.

\section{Data Analysis}

The pressurant flowrate (from the gas orifice equation) was integrated over the test duration to obtain the total pressurant mass added in each test.

$$
M_{p}=\int \dot{m}_{p} d t
$$

Pressurant collapse factors are defined as the ratio of actual pressurant requirements to an ideal amount. The ideal gas requirement for ramp pressurization was calculated as

$$
M_{p, i d}=\frac{P_{2}\left(V_{i m, 1}-V_{i m, 2}\right)}{Z_{2} R \bar{T}_{p}}
$$

where $V_{i m, 2}$ is the volume of the initial ullage mass after isentropic compression from $P_{1}$ to $P_{2}$. $V_{i m, 2}$ was obtained from hydrogen thermodynamic properties. For expulsion, the ideal mass is given by

$$
M_{p, i d}=\frac{P_{2} \Delta V_{v}}{Z_{2} R \bar{T}_{p}}
$$

A compressibility factor of unity was calculated for all tests.

Transient vapor mass calculations assumed that uniform radial temperature distributions prevailed. Discussion of the validity of this assumption is deferred until later. Using the vapor temperature measurements along the main vertical temperature rake, plus other locations when necessary to substitute for failed sensors, a temperature profile for the vapor region was obtained at discrete times during a test. The temperature profiles were individually fitted with smooth interpolated curves. Temperatures were then obtained at regular vertical intervals over the range of the vapor space and used along with the instantaneous tank pressure to get local vapor properties from a fluid properties subroutine. The data analysis code determined the volumes for each vapor segment and integrated the densityvolume relation to obtain total vapor mass at each time period.

$$
M_{v}(t)=\int \rho_{v} d v_{v}
$$

The rate of change of vapor mass versus time is equal to the instantaneous pressurant flowrate plus the mass transfer rate at the liquid-vapor interface (positive mass transfer defined as evaporation).

$$
d M_{v} / d t=\dot{m}_{p}+\dot{m}_{e}
$$

Energy added to the tank by the pressurant gas was obtained by integration of the product of flowrate and specific enthalpy.

$$
E_{p}=\int_{1}^{2} \dot{m}_{p} h_{p} d t
$$

A second, much smaller, tank energy addition term results from wall heat leak.

$$
Q_{\text {in }}=\int \dot{q}_{w} A_{w} d t
$$

Total wall energy change was determined from an analysis of wall temperature rise data.

$$
\Delta U_{w}=\sum_{i} m_{w, i} c_{w, i} \Delta T_{w, i}
$$

Total vapor energy at a given time was calculated using the specific internal energy.

$$
U_{v}(t)=\int \rho_{v} u_{v} d V_{v}
$$

Calculation of the change in vapor energy involved some uncertainty since the ullage was predominantly parahydrogen at the start of pressurization and then became a mixture as pressurant gas (normal hydrogen-75\% ortho and $25 \%$ para) was added. Since the vapor composition was not known, it was assumed that the mass fractions of para and normal hydrogen were uniform throughout the ullage and thus determined from the following mass balance.

$$
x_{p h, 2}=\frac{x_{p h, 1} M_{v, 1}+M_{e}}{M_{v, 2}}, x_{n h, 2}=\frac{x_{n h, 1} M_{v, 1}+M_{p}}{M_{v, 2}}
$$


All interfacial mass transfer was assumed to consist of parahydrogen only. Mass fractions calculated for the end of ramp tests were used as starting values for expulsions.

The change in total ullage energy relative to the initial state was calculated from the following:

$$
\begin{aligned}
\Delta U_{v}= & \left(x_{p h} U_{v, p h}+x_{n h} U_{v, n h}\right)_{2} \\
& -\left(x_{p h} U_{v, p h}+x_{n h} U_{v, n h}\right)_{1}
\end{aligned}
$$

The remaining term in an overall tank energy balance is the liquid energy increase, $\Delta U_{\ell}$, including that of the outflow, if any.

$$
\Delta U_{\ell}=\left[\int \rho_{\ell} u_{\ell} d V_{\ell}\right]_{2}-\left[\int \rho_{\ell} u_{\ell} d V_{\ell}\right]_{1}-\int_{1}^{2} \dot{m}_{o} h_{o} d t
$$

Due to the extreme difference in liquid and vapor masses, very small temperature errors on the liquid-side will lead to large errors in the energy balance. To minimize this impact, liquid energy calculations for ramp tests were restricted to the region just below the liquid-vapor interface where a warm liquid layer develops due to heating from the vapor space. Thus, the energy change of the remaining liquid was assumed to be zero. All liquid was assumed to be parahydrogen. For expulsion tests, the entire liquid mass including outflow was included in the calculations. Two tests representing the extreme cases (high pressure/fast expulsion and low pressure/slow expulsion) were analyzed using 50 percent fill as the stopping point such that detailed temperature profiles in the warm liquid surface layer were available. Complete energy balance errors ranged from 1 to 6 percent-thus leading to confidence in the measurements and the one-dimensional analysis. Since there was no interface rake at the final expulsion liquid level of 5 percent fill, liquid energy increases for overall expulsions were calculated by subtracting the energy increase of the vapor and wall from the total energy input.

$$
\Delta U_{\ell}=E_{p}+Q_{i n}-\Delta U_{v}-\Delta U w
$$

\section{Results}

Table 1 provides the complete matrix of tests. The table gives operating parameters plus an indication of the radial temperature uniformity in the tank ullage. Tank pressure versus time histories were approximately linear for ramp tests. During expulsions, the tank pressure dropped suddenly by 5 to $20 \mathrm{kPa}$ when the outflow valves were opened and then remained quasi-steady during expulsion with variations from 0 to $+3 \mathrm{kPa}$. The final pressure is listed for expulsion tests. Pressurant temperatures listed are average values. Since the pressurant line was initially cold, the average gas temperature is slightly higher for tests of longer duration and higher total gas flow. Ullage temperatures were classified as radially

\begin{tabular}{|c|c|c|c|c|c|c|}
\hline \multicolumn{7}{|c|}{ Table 1-Test Matrix } \\
\hline I.D. & Type & $\begin{array}{c}\text { Operating } \\
\text { Pressure } \\
\text { [kPa] }\end{array}$ & $\begin{array}{l}\text { Fill Level } \\
\text { Range [\%] }\end{array}$ & $\begin{array}{c}\text { Test } \\
\text { Duration } \\
\text { [min] }\end{array}$ & $\begin{array}{l}\text { Pressurant } \\
\text { Temp }[\mathrm{K}]\end{array}$ & $\begin{array}{c}\text { Radial } \\
\text { Temperature } \\
\text { Uniformity }\end{array}$ \\
\hline 488 & Ramp & $102-207$ & 87 & 0.233 & 271 & No \\
\hline 487 & Ramp & $101-203$ & 87 & 0.400 & 268 & Yes \\
\hline 489 & Ramp & $101-205$ & 87 & 0.950 & 272 & Yes \\
\hline 490 & Ramp & $103-204$ & 86 & 1.800 & 273 & Yes \\
\hline 494 & Ramp & $100-278$ & 86 & 0.400 & 284 & No \\
\hline 493 & Ramp & $102-278$ & 87 & 0.650 & 284 & Approx. \\
\hline 492 & Ramp & $102-277$ & 87 & 1.533 & 282 & Yes \\
\hline 491 & Ramp & $101-275$ & 87 & 3.000 & 280 & Yes \\
\hline 498 & Ramp & $100-203$ & 50 & 1.017 & 290 & $\mathrm{No}^{*}$ \\
\hline 497 & Ramp & $100-203$ & 50 & 1.933 & 289 & No \\
\hline 505 & Ramp & $101-203$ & 49 & 4.900 & 291 & Yes \\
\hline 499 & Ramp & $99-272$ & 50 & 1.633 & 292 & $\mathrm{No}^{*}$ \\
\hline 500 & Ramp & $100-276$ & 50 & 3.133 & 292 & No \\
\hline 501 & Ramp & $102-276$ & 49 & 8.217 & 291 & Yes \\
\hline 506 & Expulsion & 201 & $87-5$ & 12.667 & 294 & Approx. \\
\hline 507 & Expulsion & 204 & $87-5$ & 18.100 & 294 & Yes \\
\hline 508 & Expulsion & 202 & $87-5$ & 32.900 & 294 & Yes \\
\hline 510 & Expulsion & 275 & $86-5$ & 12.350 & 294 & Approx. \\
\hline 509 & Expulsion & 277 & $86-4$ & 18.150 & 295 & Yes \\
\hline 511 & Expulsion & 279 & $87-5$ & 32.967 & 292 & Yes \\
\hline
\end{tabular}
uniform if radial variations did not exceed 2 percent of the maximum ullage gas temperature range. In tests where nonuniformities were 
observed, the variations occurred along the top radial temperature rake, with the higher temperature being at the position closest to the pressurant diffuser outlet. In some cases the departure from uniformity is considered small and restricted to the lowest density region of the ullage; these cases are denoted as having "approximate" uniformity. Two of the ramp tests at 50 percent fill showed extreme nonuniformity with radial variations observed along both radial temperature rakes in the ullage space-these tests are denoted with an asterisk. As expected, the nonuniformity is encountered at higher pressurant gas flowrates (jet-like flow at the diffuser outlet) occurring in quicker ramp processes, higher operating pressure and lower fill level (i.e., larger ullage volume to pressurize).

Figure 2 shows the total pressurant consumption for the pressurization process as a function of the ramp duration. As expected, the longer the ramp time, the more pressurant gas required. Also observed are the increasing pressurant requirements as the final tank pressure increases and as the tank liquid fill level decreases (increasing ullage volume). While this difference in actual pressurant mass for ramps may be small in comparison to pressurant needs for expulsions, it could become substantial in missions requiring

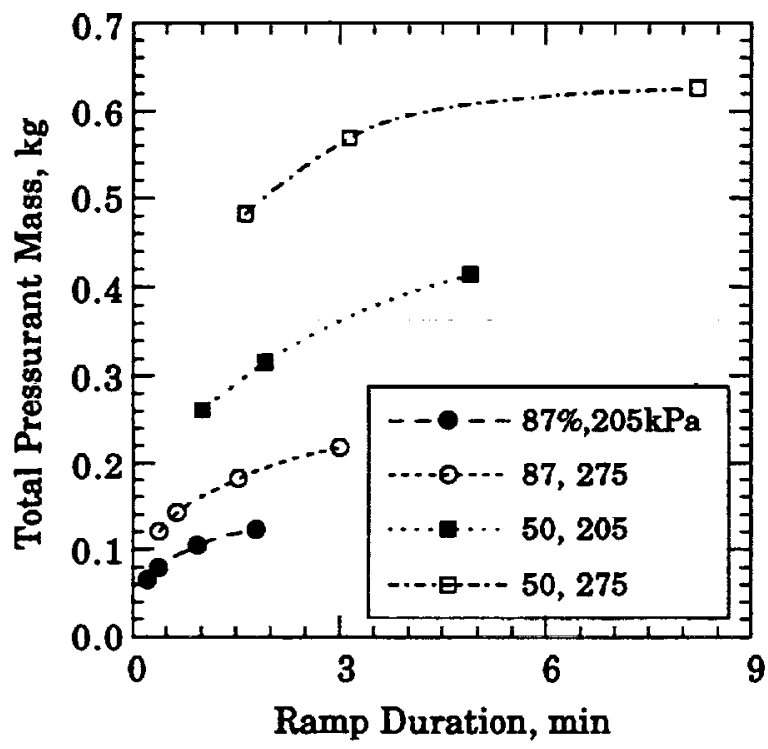

Figure 2 - Effect of Ramp Duration on Total Required Pressurant Mass.

multiple pressurizations of the supply tank. Collapse factors for the ramp tests are shown in Fig. 3. As expected, the faster ramps are more efficient-with collapse factors approaching 1.5 . Some of the longer ramp times led to collapse factors greater than 3. At both fill levels, the ramps to higher final pressure show lower collapse factors for a given ramp time-thus indicating greater thermodynamic efficiency, albeit at higher pressurant mass requirements. Present results are thus consistent with earlier results ${ }^{2,3}$ for trends with ramp time and fill level. Higher values for the present ramp collapse factors (1.6-3.2 vs. 1.1-1.8 for comparable fill levels) are due to the higher inlet gas temperature and lower final pressure in the present work. A trend also observed in the earlier work is the higher collapse factors at smaller ullage volume (larger fill level). This result was attributed to the colder average initial wall temperature at higher fill level which creates a larger temperature difference and higher rates of gas-to-wall heat transfer. Other factors are the higher wall surface-to-vapor volume ratio at 87 percent fill and the proximity of the diffuser to the liquid surface. The greater efficiency of the higher operating pressure indicates a lower fraction of pressurant energy is lost from the ullage space-this fraction is lower primarily because more pressurant energy is supplied to the ullage at the higher operating pressure and does not indicate reduced energy transfer. There is an increase in the sensitivities of required pressurant mass and collapse factor to time with decreasing time; performance benefits or penalties will be most significant when ramp duration is brief.

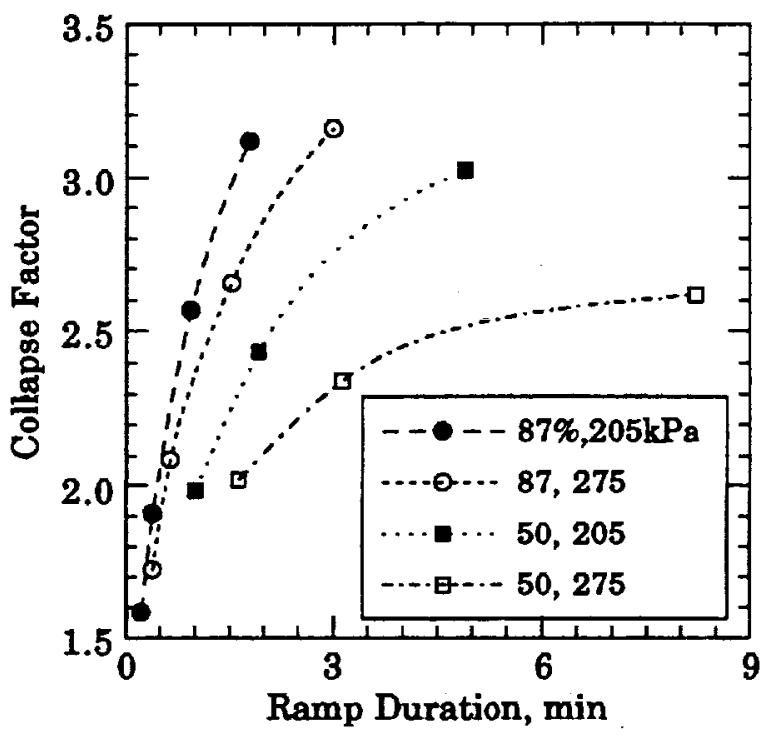

Figure 3 - Collapse Factors for Ramp Pressurization Experiments.

The effect of expulsion time on total pressurant consumption is shown in Fig. 4. Again, the amount of pressurant gas required during the expulsion period increases with increasing tank pressure. The increase in pressurant mass as the expulsion time increases becomes less at longer expulsion durations-at $205 \mathrm{kPa}$ this trend is not apparent due to small variations in expulsion pressure. 


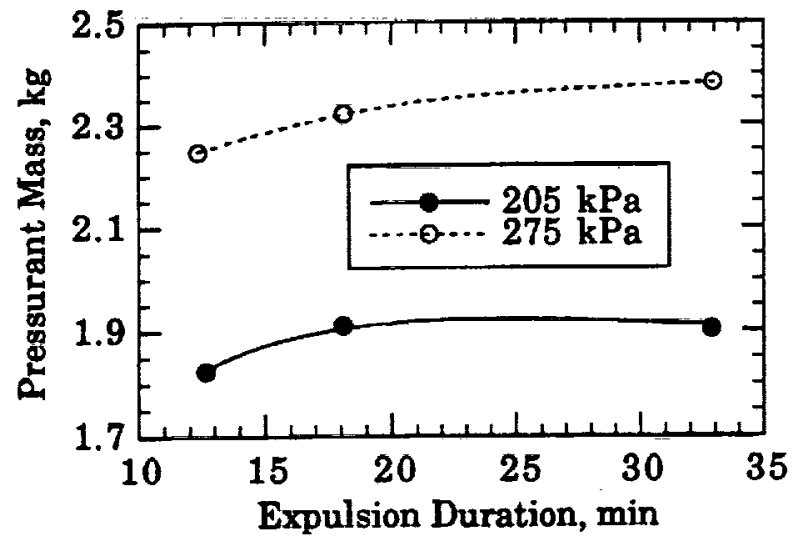

Figure 4 - Effect of Expulsion Duration on Total Required Pressurant Mass.

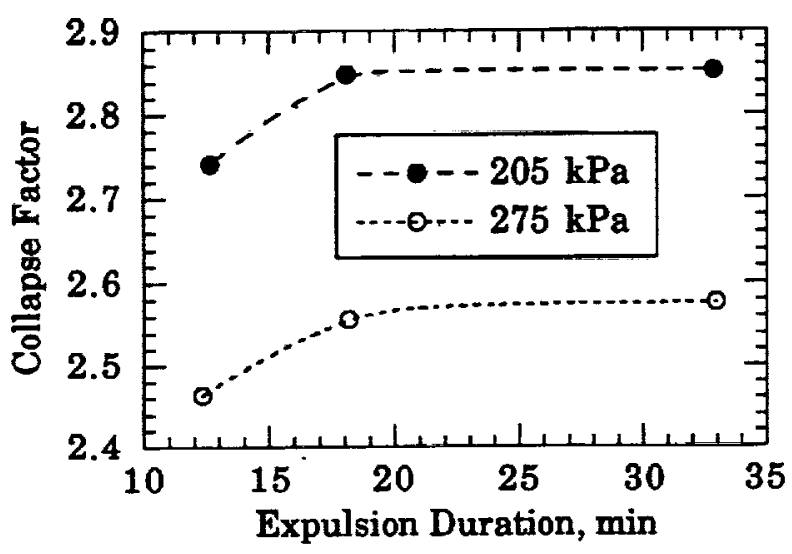

Figure 5 - Collapse Factors for Expulsion Experiments.

Collapse Factors for the expulsion tests are shown in Fig. 5. Trends are similar to the ramp results with collapse factor increasing with expulsion duration and decreasing with increasing expulsion pressure. Figs. 4 and 5 show that expulsion time has greatly reduced impact on pressurant requirements after a sufficiently long expulsion duration as been reached-approximately 18-20 min for these tests. These results indicate that beyond some characteristic time the required pressurant mass is less dependent upon expulsion time and that energy transfer from the vapor space occurs at a reduced rate. Figure 5 indicates a dependence of collapse factor on pressure level. This trend of decreasing collapse factor with increasing pressure is consistent with the above results for ramp pressurization. Results of ref. 3 did not exhibit this trend with pressure. Values of the present collapse factors (2.4-2.9) are comparable to earlier results ${ }^{2,3}$ (2.3-3.3)-direct comparisons are difficult because of variations in pressurant gas temperature and expulsion pressure. It also appears that collapse factors are larger in smaller volume tanks; the ullage surfaceto-volume ratio could be an additional controlling parameter.

Calculated interfacial mass transfer quantities are not reliable for ramp tests with radial vapor temperature nonuniformities. Remaining tests do not show conclusive results, other than that interfacial mass transfer is at most about 20 percent of the pressurant mass and could be either evaporation or condensation. Condensation was the more prevalent mode at 87 percent fill, possibly due to the close proximity of the diffuser outlet to the liquid-vapor interface. Mass and energy balance results are documented in Table 2.

The present energy balance calculations are also unreliable when radial temperature gradients exist. For some ramp tests with radially uniform vapor conditions, it was found that the calculated energy increase in the tank system still greatly exceeded the energy input. This result only occurred with the 87 percent fill tests and it is hypothesized that radial temperature variations also existed in the warm liquid layer near the interface. Only two ramp tests resulted in energy balance errors less than 10 percent-these were the tests at 50 percent fill with the longest ramp durations. For these tests, 49 percent of the incoming energy was lost to wall heating and 4043 percent resulted in vapor energy increase. The liquid heating fraction was calculated to be from 815 percent. For ramp tests, the heat leak contribution to total energy input is small; from 0.2 to 0.7 percent of the total. Figure 6 shows the wall heating results-this data is considered valid for all ramp tests. Data for varying fill level and final ramp pressure appear to fall on a single curve with wall energy change going to zero as ramp duration approaches zero. As the time becomes large, the curve of wall energy fraction flattens considerably.

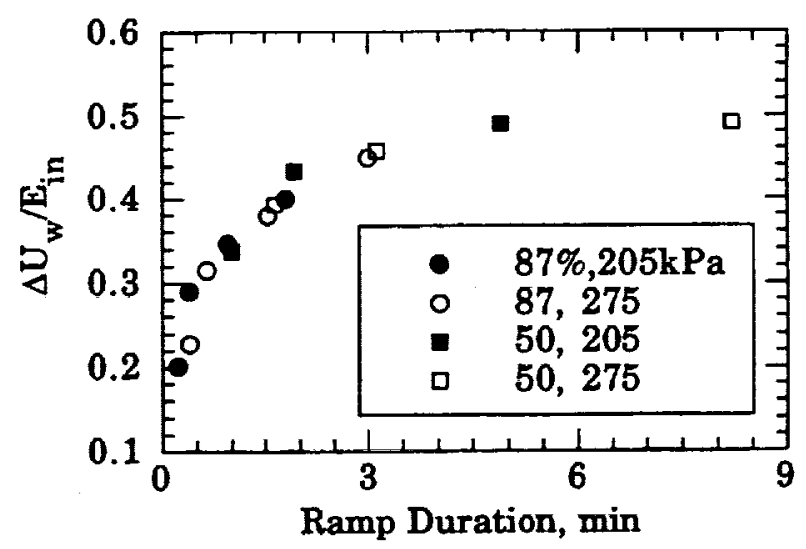

Figure 6 - Wall Energy Increase Fraction for Ramp Experiments. 


\begin{tabular}{|c|c|c|c|c|c|c|c|c|}
\hline \multicolumn{9}{|c|}{ Table 2-Mass and Energy Balance Results } \\
\hline I.D. & $M_{p}[\mathrm{~kg}]$ & $M_{e}[\mathrm{~kg}]$ & $x_{p h, 2}$ & $E_{p}[\mathrm{~kJ}]$ & $Q_{\text {in }}[k J]$ & $\Delta E_{v}[\mathrm{~kJ}]$ & $\Delta E_{w}[\mathrm{~kJ}]$ & $\Delta E_{\ell}[\mathrm{kJ}]$ \\
\hline 488 & 0.0653 & 0.006 & 0.89 & 248 & 0.5 & 159 & 50 & 194 \\
\hline 487 & 0.0793 & 0.001 & 0.87 & 299 & 0.8 & 164 & 87 & 175 \\
\hline 489 & 0.1041 & -0.013 & 0.82 & 398 & 1.8 & 177 & 138 & 170 \\
\hline 490 & 0.1222 & -0.025 & 0.80 & 469 & 3.5 & 181 & 189 & 204 \\
\hline 494 & 0.1203 & -0.012 & 0.78 & 481 & 0.8 & 309 & 109 & 420 \\
\hline 493 & 0.1414 & .0 .051 & 0.74 & 565 & 1.3 & 292 & 178 & 480 \\
\hline 492 & 0.1812 & -0.027 & 0.71 & 719 & 3.0 & 309 & 274 & 438 \\
\hline 491 & 0.2173 & -0.027 & 0.66 & 856 & 5.8 & 315 & 387 & 411 \\
\hline 498 & 0.2607 & 0.016 & 0.83 & 1062 & 2.0 & 652 & 360 & 256 \\
\hline 497 & $0.315 i$ & -0.010 & 0.80 & 1280 & 3.7 & 653 & 556 & 223 \\
\hline 505 & 0.4141 & -0.013 & 0.78 & 1695 & 9.5 & 676 & 836 & 152 \\
\hline 499 & 0.4825 & 0.000 & 0.71 & 1983 & 3.2 & 1105 & 781 & 381 \\
\hline 500 & 0.5685 & 0.004 & 0.66 & 2332 & 6.1 & 1137 & 1069 & 426 \\
\hline 501 & 0.6255 & 0.101 & 0.66 & 2560 & 15.9 & 1117 & 1265 & 392 \\
\hline 506 & 1.8244 & 0.294 & 0.30 & 7533 & 24.5 & 2312 & 4206 & - \\
\hline 507 & 1.9114 & 0.275 & 0.29 & 7911 & 35.0 & 2356 & 4566 & - \\
\hline 508 & 1.9029 & 0.505 & 0.33 & 7865 & 63.6 & 2324 & 4481 & - \\
\hline 510 & 2.2480 & 0.307 & 0.24 & 9299 & 23.9 & 3063 & 4926 & - \\
\hline 509 & 2.3218 & 0.406 & 0.25 & 9625 & 35.1 & 3091 & 5184 & - \\
\hline 511 & 2.3823 & 0.581 & 0.29 & 9784 & 63.7 & 3102 & 5310 & - \\
\hline
\end{tabular}

(Note: italicized results are most likely erroneous due to radial temperature gradients in vapor and/or liquid. Values are included for completeness only.)

Figure 7 provides the interfacial mass transfer fraction for the expulsion tests. The mode was evaporation in all cases and the amount of evaporated mass increases as a fraction of the pressurant requirement as the expulsion time increases. Although the fidelity of this data is marginal, the results demonstrate the significance of interfacial mass transfer in the expulsion process. The current results follow the trend of the earlier work ${ }^{2,3}$ with increasing evaporation/ decreasing condensation as the expulsion duration becomes longer.

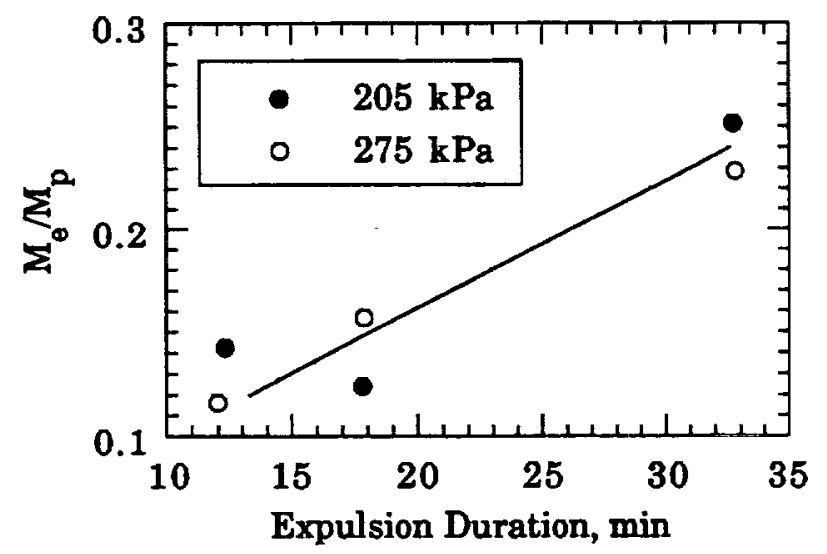

Figure 7 - Total Interfacial Mass Transfer for Expulsion Experiments.

Results of the energy balance analysis are shown in Fig. 8 for the expulsion tests. The distribution of energy input becomes independent of time after 18 min. At $275 \mathrm{kPa}$, about 53-54 percent of the energy added to the tank goes into wall heating, 32-33 percent remains in the ullage and the remainder, 14-15 percent, is lost to liquid heating. Results for the $205 \mathrm{kPa}$ expulsions are similar, but with a slightly different distribution- $-56-57$ percent goes into wall heating, $29-30$ percent remains in the ullage and 13-14 percent lost to the liquid. For expulsions, the heat leak contribution to total energy input is from 0.3 to 0.8 percent of the total. The differing values for vapor heating fraction at the two pressures is the cause of the

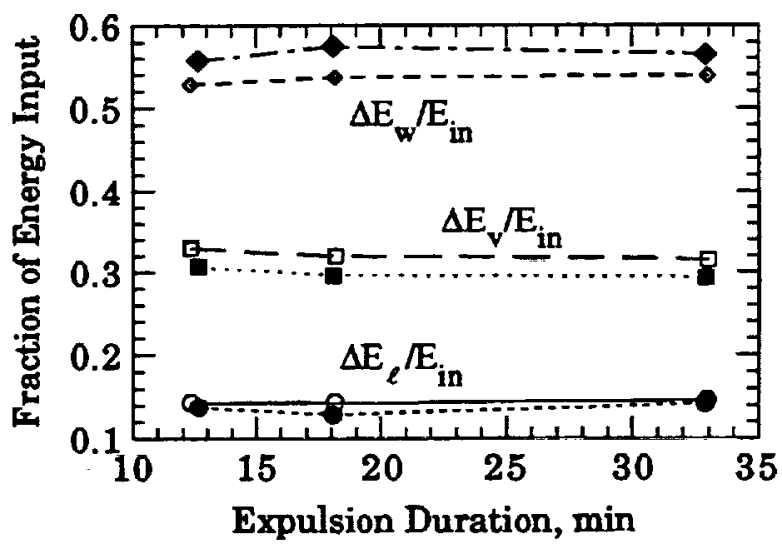

Figure 8 - Distribution of Tank Energy Input for Expulsion Tests (solid symbols-205 $\mathrm{kPa}$, open-275 $\mathrm{kPa}$ ).

collapse factor pressure dependence shown in Fig. 5. Earlier tests ${ }^{2,3}$ show substantially reduced wall heating and increased vapor heating fractions as 
the expulsion time decreases-the current data shows that the rate of change of the energy distribution fractions becomes small at longer expulsion times. Comparison of all data suggests that the characteristic time at which expulsion duration has little significance becomes greater as the tank size increases (decreasing tank surfaceto-volume ratio).

Differences in the final temperature profiles at 5 percent fill for high pressure expulsions are evident in Fig. 9. There is an overall increase in end-ofexpulsion vapor temperature as the expulsion duration decreases. Also shown is one of the initial temperature profiles at 87 percent fill-the starting profiles are essentially identical for other tests in the figure. The temperature profiles display the increased cooling of the ullage region as the expulsion duration increases-heat transfer is from the hotter vapor to the tank wall and liquid-vapor interface and results in an increase in the vapor density and mass. As the final temperatures decrease, the total energy change of the ullage increases due to the increased mass of the vapor. Similar final temperature profiles exhibiting vapor cooling with increasing process duration were observed for the low expulsion pressure and for ramp tests.

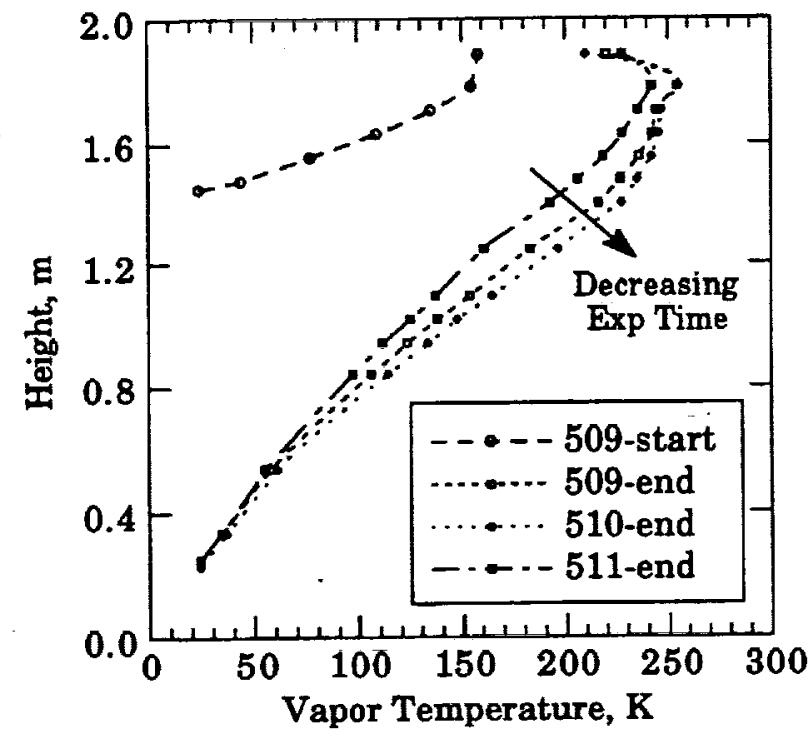

Figure 9 - Initial and Final Temperature Profiles for Expulsion Tests at $275 \mathrm{kPa}$

Vapor mass increase during the expulsion process is shown in Fig. 10 for the tests conducted at 275 $\mathrm{kPa}$. Results for the $205 \mathrm{kPa}$ tests are similar but not shown. Vapor mass increases linearly with time and the rate of increase decreases as the expulsion duration increases. The slope of these curves is the quantity $d M_{v} / d t$ in $\mathbf{E q}(5)$ and is approximately constant for each of the expulsion tests. Note that the final mass increases with increasing expulsion time-this result is due to the cooling of the vapor space that increases with time as discussed in connection with Fig. 9. Since the pressurant gas flow rate and $d M_{v} / d t$ remain essentially constant during outflow, it follows from Eq. (5) that the interfacial mass transfer rate is also approximately constant. This occurs although the interfacial area and (presumably) warm liquid layer thickness are changing throughout the expulsion process.

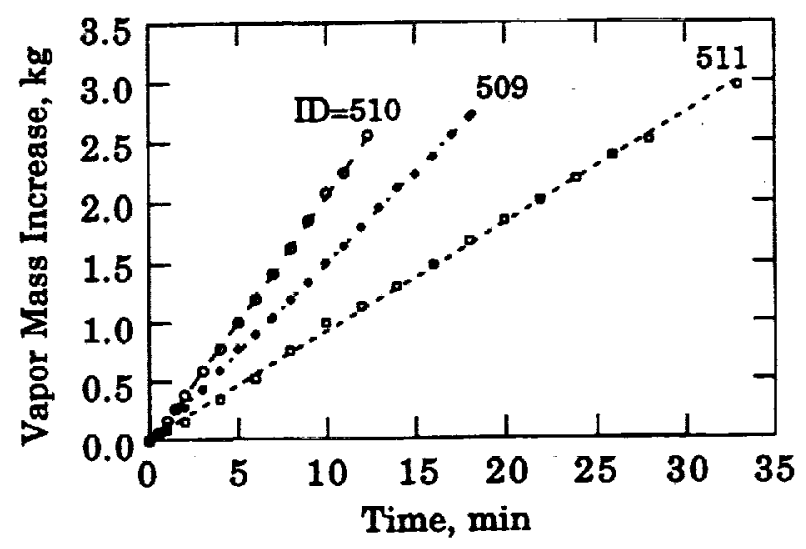

Figure 10 - Vapor Mass During Expulsion, $275 \mathrm{kPa}$.

The computed vapor mass increase during ramp tests to $275 \mathrm{kPa}$ at $87 \%$ fill are shown in Fig. 11 . The two longer duration tests (I.D. 491 and 492) exhibit smooth upward curving profiles. The fast ramp test (494) is shown for comparison and displays scattered data points which are attributed to the non-uniform radial temperatures observed in this test-therefore, the data shown for 494 should not be considered accurate. Note that the same trends occur here as for the expulsion tests. As the ramp duration increases, the final vapor mass increases and the slope of the curve becomes less. The curves with smooth profiles are well-represented by second order polynomial curve fits from which $d M_{v} / d t$ is obtained. With $d M_{v} / d t$ and the pressurant flowrate known as functions of time, the transient interfacial mass transfer can be determined. Figure 12 shows the result for test 491 . Unlike the expulsion tests, the mass transfer rate is not constant. The mass transfer is initially evaporation as expected since the tank is selfpressurizing when the pressurant flow begins. As the pressurant flowrate begins, the liquid becomes subcooled and the interface temperature increases-causing the evaporation rate to drop and the mass transfer mode switches to condensation as shown. For this particular case, the ramp duration is sufficiently long for the condensation rate to drop and the mass transfer 
approaches the evaporation mode again. For shorter ramps, this approach to evaporation does not occur.

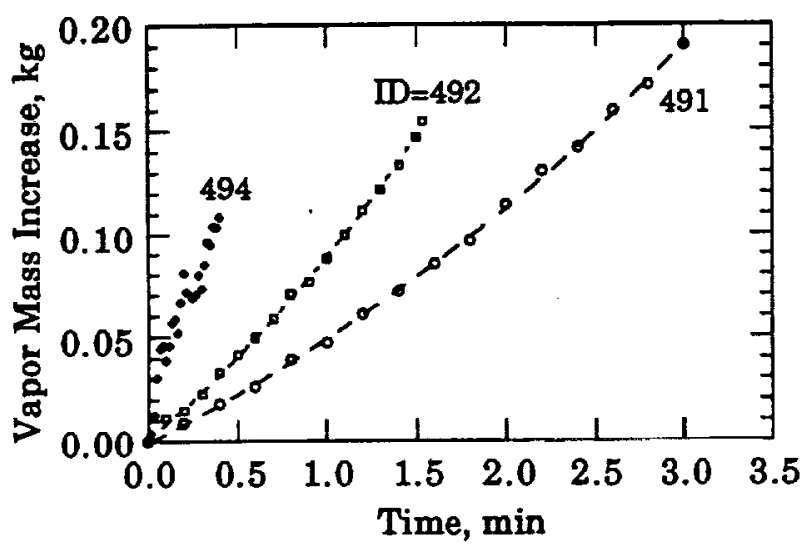

Figure 11 - Vapor Mass During Ramp, 87\% Fill, $275 \mathrm{kPa}$ Final Tank Pressure.

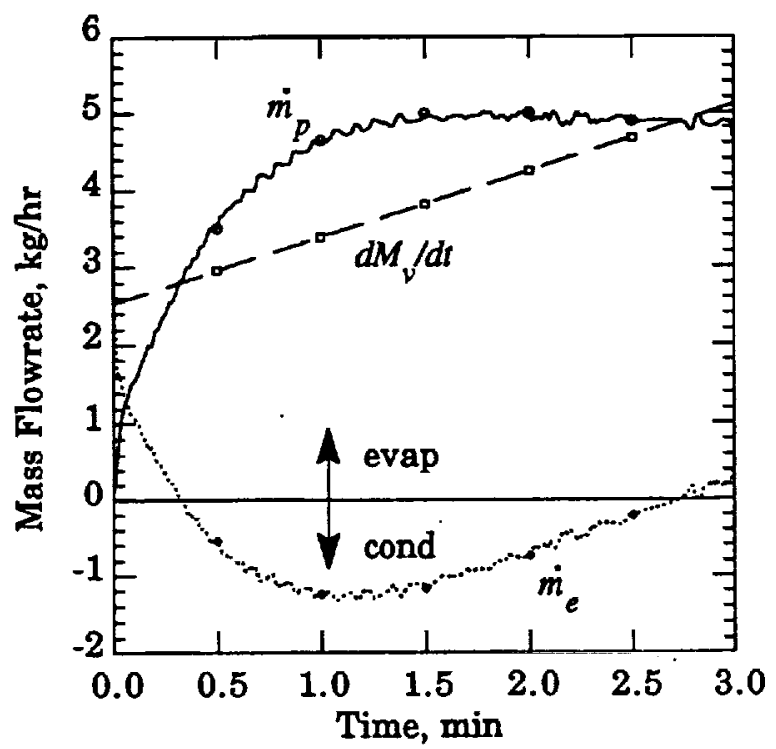

Figure 12 - Transient Vapor Mass Balance During Ramp Test I.D. 491, 87\% Fill, $275 \mathrm{kPa}$ Final Tank Pressure.

\section{Conclusions}

Pressurant gas requirements for both ramp and expulsion processes increase as the operational time is lengthened. For expulsions, it has been demonstrated that the rate of change of this increase becomes small at sufficiently long expulsion durations; based on observed trends, this effect also appears to hold for the ramp process. The diminishing rate of change is attributed to the decreased rate of energy transfer from the ullage gas due to decreasing temperature gradients near the tank wall and liquid surface as the process duration becomes long.

The present work combined with previous results gives reasonable indications of the quantitative dependence of the collapse factor on tank pressure, pressurant gas temperature, wall thickness and process duration for the normal gravity environment. With careful examination of collapse factor data and trends, one can use collapse factors to estimate pressurant gas requirements. Additional tests would be useful to extend the current range of collapse factor data where necessary.

In the present study, the distribution of pressurant energy to ullage, liquid and wall heating was insensitive to the process time as expulsions became long. The largest portion of input energy goes into wall heating -50 percent or more for expulsions and long ramps. It is hypothesized that for extremely long durations or tanks with less heat capacity, the wall heat capacity would be reached; at this point the liquid heating fraction would increase. In this situation, the wall thickness would have greater influence.

Interfacial mass transfer plays a significant role in ramp or expulsion processes of practical duration. Although accurate data remains difficult to obtain, it is recognized that dependable analytical tools will require proper modeling and improved measurement capabilities of interfacial transport phenomena.

It is clear that one-dimensional analysis is not always adequate for analysis of real systems. Radial gradients were sometimes observed in the vapor region and suspected in the liquid. This was apparent in ramp tests involving rapid pressurization and high liquid fill level. One-dimensional analysis of the expulsion process was found to be acceptable for the present work, but this approach should be treated with caution.

\section{References}

1. Van Dresar, N.T., "Pressurization of Cryogens: A Review of Current Technology and its Applicability to Low-Gravity Conditions," AIAA paper 92-3061, 1992.

2. Stochl, R.J., et al, “Gaseous-Hydrogen Requirements for the Discharge of Liquid Hydrogen From a 1.52 Meter- (5-ft-) Diameter Spherical Tank," NASA TN D-5336, 1969.

3. Stochl, R.J., et al, "Gaseous-Hydrogen Pressurant Requirements for the Discharge of Liquid Hydrogen From a 3.96 Meter- (13-ft-) Diameter Spherical Tank," NASA TN D-5387, 1969. 
Public reporting burden for this collection of information is estimated to average 1 hour per response, including the time lor reviewing instructions, searching existing data sources, gathering and maintaining the dala needed, and completing and reviowing the collection of information. Send comments regarding tits buden estimale or any orther aspect of tis collection of inlormation, including suggest 22202-4302, and to the Office of Management and Budget, Paperwork Reduction Project (0704-0188). Washington, DC 20503.
1. AGENCY USE ONLY (Leave blank)
2. AEPORT DATE
3. REPORT TYPE AND DATES COVERED
December 1993
Technical Memorandum

4. TITLE AND SUBTITLE

Pressurization and Expulsion of a Flightweight Liquid Hydrogen Tank

6. AUTHOR(S)

N.T. Van Dresar and R.J. Stochl

7. PERFORMING ORGANIZATION NAME(S) AND ADDRESS(ES)

National Aeronautics and Space Administration

Lewis Research Center

Cleveland, Ohio 44135-3191

9. SPONSORINGMONITORING AGENCY NAME(S) AND ADDRESS(ES)

National Aeronautics and Space Administration

Washington, D.C. 20546-0001
5. FUNDING NUMBERS

WU-506-42-73

8. PERFORMING ORGANIZATION REPORT NUMBER

E-8269

11. SUPPLEMENTARY NOTES

Prepared for the 29th Joint Propulsion Conference and Exhibit cosponsored by the AIAA, SAE, ASME, and ASEE,

Monterey, California, June 28-30, 1993. Responsible person, R.J. Stochl, (216) 977-7522

NASA TM-106427

AIAA-93-1966

12a. DISTRIBUUTIÓNV́AVAILABILITY STATEMENT

12b. DISTAIBUTION CODE

Unclassified - Unlimited

Subject Category 34

13. ABSTRACT (Maximum 200 words)

Experimental results are presented for pressurization and expulsion of a flightweight $4.89 \mathrm{~m}^{3}$ liquid hydrogen storage tank under normal gravity conditions. Pressurization and expulsion times were parametrically varied to study the effects of longer transfer times expected in future space flight applications. It was found that the increase in pressurant consumption with increased operational time is significant at shorter pressurization or expulsion durations and diminishes as the duration lengthens. Gas-to-wall heat transfer in the ullage was the dominant mode of energy exchange, with more than 50 percent of the pressurant energy being lost to tank wall heating in expulsions and the long duration pressurizations. Advanced data analysis will require a multidimensional approach combined with improved measurement capabilities of liquid-vapor interfacial transport phenomena.

\section{SUBJECT TERMS}

Pressurization; Fluid transfer

15. NUMBER OF PAGES

11

16. PRICE CODE

$\mathrm{A03}$

17. SECURITY CLASSIFICATION OF REPORT

Unclassified
18. SECURITY CLASSIFICATION OF THIS PAGE

Unclassified
19. SECURITY CLASSIFICATION OF ABSTRACT

Unclassified 